\title{
Comparative Study of the Prognosis of Ischemic Cerebral Stroke Subtypes
}

\author{
Aktham Ismail Alemam
}

\begin{abstract}
Background: The aim of the study was to search if prognosis of ischemic cerebral stroke is affected by its subtypes with regard to its etiology, anatomical site, radiological size, and clinical severity.

Methods: This study was conducted on 43 patients of both sexes with ischemic cerebral stroke admitted to the Neurology Department of Menoufia University Hospitals. Their ages were ranging from 48 to 72 years old and the mean age of cases was $61.26 \pm 5.37$, while in controls was $58.50 \pm 4.70$. Clinical severity of stroke was assessed using National Institutes of Health Stroke Scale (NIHSS). The etiological subtypes of stroke were classified according to Trial of Organization 10172 in Acute Stroke Treatment classification. The anatomical site of stroke was evaluated by using the Oxford Community Stroke Project classification. Its size was measured by neuroimaging. Favorable outcome (FO) was defined as modified Rankin scale (0 2) while unfavorable outcome (UO) was defined as modified Rankin scale (3 - 6) after 3 months of onset of the stroke.
\end{abstract}

Results: The UO was correlated with the large vessel stroke $(\mathrm{P}<$ $0.001)$, severe and very severe NIHH scores $(\mathrm{P}<0.047$ and $\mathrm{P}<0.041$, respectively), total anterior circulation stroke $(\mathrm{P}<0.001)$, and lesion size $>3 \mathrm{~mm}(\mathrm{P}=0.007)$. The FO was correlated with small vessel disease $(\mathrm{P}<0.001)$, mild NIHSS score $(\mathrm{P} \leq 0.0001)$, lacunar infarction $(\mathrm{P}$ $<0.001)$, and infarct size $<1.5 \mathrm{~mm}(\mathrm{P}=0.001)$.

Conclusion: The outcome of cerebral ischemic stroke may be affected by its subtype. This may help the clinician to tailor better individual plan of management.

Keywords: Stroke; Subtypes; Prognosis

\section{Introduction}

On evaluation of stroke patients early after the onset of the dis-

Manuscript submitted September 3, 2017, accepted September 21, 2017

Neurology Department, Menoufia School of Medicine, Al Minufya, Egypt. Email: e_aktham@yahoo.com

doi: https://doi.org/10.14740/jnr450w ease, the neurologic examination alone may give false impression about the prognosis. Determination of the factors that affect this prognosis may help the treating physician to tailor the plan of management for the individual patient, and give the patient and his family more education about the course of the disease.

Ischemic cerebral stroke may be classified by different systems. It is etiologically classified according to the Trial of Organization 10172 in Acute Stroke Treatment (TOAST) classification into atherosclerotic, cardio-embolic, lacunar, other determined, and undetermined etiology [1]. The Oxford Community Stroke Project (OCSP) classification divided the ischemic stroke anatomically into total anterior circulation stroke (TAC), partial anterior circulation stroke (PAC), lacunar stroke (LAC), and posterior circulation stroke (POC) [2]. Neurologic impairment is measured quantitatively in many research studies, and increasingly in clinical practice, by use of the National Institutes of Health Stroke Scale (NIHSS), which measures neurologic impairment using a 15-item scale [3]. With regard to the size of the infarction based on radiological evaluation, it is considered small if it was below $1.5 \mathrm{~cm}$, medium size if 1.5 $3 \mathrm{~cm}$, and large size if it was more than $3 \mathrm{~cm} \mathrm{[4].}$

The aim of this study was to search if prognosis of ischemic cerebral stroke is affected by its subtypes with regard to its etiological causes, anatomical sites, radiological sizes, and clinical severity.

\section{Patients and Methods}

This study was conducted on 43 patients of both sexes with ischemic cerebral stroke admitted to the Neurology Department of Menoufia University Hospitals. Their ages were ranging from 48 to 72 years old and the mean age of cases was 61.26 \pm 5.37 , while in controls was $58.50 \pm 4.70$. Among the cases there were 22 males $(51.2 \%)$ and 21 females (48.8\%). Before starting the study, the ethics committee approved it and the informed consents were obtained from the patients.

\section{Inclusion criteria}

Patients with first time ischemic stroke, in the first $24 \mathrm{~h}$ of onset, confirmed by neuroimaging were included. The patients received antithrombotic treatment on admission in the form of antiplatelets plus or minus anticoagulants, but no one received thrombolytic treatment. 
Table 1. Correlation Between Etiological Stroke Subtypes and Stroke Outcome

\begin{tabular}{lllllll}
\hline \multirow{2}{*}{ TOAST } & \multicolumn{3}{c}{ Outcome $(\mathbf{N}, \mathbf{\%})$} & Test & Pvalue \\
\cline { 2 - 6 } & Favorable $(\mathbf{N}=\mathbf{2 8})$ & Unfavorable $(\mathbf{N}=\mathbf{1 5})$ & 13.3 & 0.25 & 0.239 \\
\hline Cardio-embolic stroke & 3 & 10.7 & 2 & 66.6 & 2.92 & 0.003 \\
Large vessel stroke & 6 & 21.4 & 10 & 6.7 & 3.22 & $<0.001$ \\
Small vessel stroke & 16 & 57.2 & 1 & 13.3 & 0.25 & 0.239 \\
\hline Cryptogenic stroke & 3 & 10.7 & 2 & & & \\
\hline
\end{tabular}

\section{Exclusion criteria}

Patients with hemorrhagic stroke, history of old cerebral stroke by history or as seen on neuroimaging on admission, and the patients who died due to the systemic non-neurological complications.

\section{Clinical assessment}

The stroke condition was evaluated with detailed and careful history taking, general (to assess the risk factors) and neurological examination. Clinical evaluation of stroke severity was assessed using NIHSS within the first $24 \mathrm{~h}$ of admission. Patients with a score greater than 25 are considered to have a very severe neurological impairment, while 16 - 25 is severe, $6-15$ is moderate and 6 is mild neurological impairment [5]. Stroke outcome was evaluated by using modified Rankin scale (MRS) after 3 months of onset of stroke. Favorable outcome (FO) was defined as MRS of 0 - 2 while unfavorable outcome (UO) defined as MRS of 3 - 6 [6].

\section{Laboratory assessment}

Blood samples were taken at admission before treatment. Routine tests included complete blood picture, liver function tests, kidney function tests, fasting and $2 \mathrm{~h}$ blood sugar, and erythrocyte sedimentation rate.

\section{Radiological assessment}

Initial and follow-up brain computerized tomography (CT) and/or magnetic resonance imaging (MRI) was done at ad- mission, focusing on the early infarction signs (focal brain swelling, early hypodensity, attenuation of basal ganglia, or hyperdense artery sign) and detection of the site and size of infarction, and also for exclusion of cerebral hemorrhage or any other focal lesion. All patients underwent echocardiography and duplex carotids. Some of them also had magnetic resonance angiography on cerebral blood vessels.

The anatomical site of stroke was evaluated by using the OCSP. It relies primarily on the initial symptoms, based on the extent of the symptoms.

The etiological subtypes of stroke were classified according to TOAST classification.

\section{Statistical analysis}

Quantitative data were described using range (minimum and maximum), mean, standard deviation and median. Significance of the obtained results was judged at the 5\% level. Chisquare test, Fisher's exact test, F-test, and analysis of variance (ANOVA) were used.

\section{Results}

In this study we searched if there is a correlation between the outcome of ischemic stroke and its subtypes regarding its clinical severity using NIHSS, its etiology using TOAST, its site using OCSP and its infarction size using neuroimaging.

According to the relation between the outcome of ischemic stroke and different stroke subtypes, there was a highly statistical significant correlation between large vessel stroke $(66.6 \%)$ and $\mathrm{UO}$ in ischemic stroke patients $(\mathrm{P}<0.001)$. While the small vessel disease type was correlated with FO $(\mathrm{P}<$ 0.001) (Table 1).

Table 2. Correlation Between Stroke Severity on Admission and Stroke Outcome

\begin{tabular}{lllllll}
\hline \multirow{2}{*}{ NIHSS } & \multicolumn{3}{c}{ Outcome $(\mathbf{N}, \mathbf{\%})$} & Test & P value \\
\cline { 2 - 5 } & \multicolumn{2}{c}{ Favorable $(\mathbf{N}=\mathbf{2 8})$} & \multicolumn{2}{c}{ Unfavorable $(\mathbf{N}=\mathbf{1 5})$} & & \\
Mild & 17 & 60.7 & 0 & 0.0 & 3.88 & $<0.001$ \\
Moderate & 11 & 39.3 & 9 & 60.0 & 1.29 & 0.193 \\
Severe & 0 & 0.0 & 2 & 13.3 & 1.97 & 0.047 \\
Very severe & 0 & 0.0 & 4 & 26.7 & 2.86 & 0.041 \\
\hline
\end{tabular}

NIHSS: National Institutes of Health Stroke Scale. 
Table 3. Correlation Between the Site of Stroke and its Outcome

\begin{tabular}{|c|c|c|c|c|c|c|}
\hline \multirow{3}{*}{$\begin{array}{l}\text { OCSP } \\
\text { PACS }\end{array}$} & \multicolumn{4}{|c|}{ Outcome (N, \%) } & \multirow{3}{*}{$\begin{array}{l}\text { Test } \\
1.52\end{array}$} & \multirow{3}{*}{\begin{tabular}{|l} 
P value \\
0.126
\end{tabular}} \\
\hline & \multicolumn{2}{|c|}{ Favorable $(\mathrm{N}=\mathbf{2 8})$} & \multicolumn{2}{|c|}{ Unfavorable $(\mathrm{N}=15)$} & & \\
\hline & 10 & 35.72 & 9 & 60 & & \\
\hline POCS & 2 & 7.14 & 1 & 6.7 & 0.05 & 0.952 \\
\hline LACS & 16 & 57.14 & 1 & 6.7 & 3.22 & 0.001 \\
\hline TACS & 0 & 0 & 4 & 26.6 & 2.86 & 0.004 \\
\hline
\end{tabular}

OCSP: Oxford Community Stroke Project; PACS: partial anterior circulation stroke; POC: posterior circulation stroke; LAC: lacunar stroke; TAC: total anterior circulation stroke.

There was a highly statistical significant correlation between mild NIHSS score and FO of ischemic stroke $(\mathrm{P} \leq$ $0.0001)$. There was significant correlation between severe and very severe NIHSS scores, respectively, and UO of ischemic stroke $(\mathrm{P}<0.047$ and $\mathrm{P}<0.041)$. No significant correlation was present between moderate NIHSS score and outcome of ischemic stroke $(\mathrm{P}<0.193)$ (Table 2).

There was highly statistical significant correlation between the UO and TAC $(26.6 \%)(\mathrm{P}<0.001)$, and between lacunar infarction and FO of ischemic stroke $(57.14 \%)(\mathrm{P}<$ 0.001) (Table 3).

There was highly statistical significant correlation between lesion size $<1.5 \mathrm{~mm}$ and $\mathrm{FO}$ of ischemic stroke patients $(64.2 \%)(\mathrm{P}=0.001)$, and between lesion size $>3 \mathrm{~mm}$ and the UO $(\mathrm{P}=0.007)$ (Table 4).

\section{Discussion}

There are many studies about the relation between the etiology of ischemic stroke and its prognosis. This study showed that the stroke due to large vessel disease was correlated with the most UO. This is in agreement with Spring et al [7] and Lima et al [8] who proved that patients with strokes of large artery etiology tend to have worse prognosis for recovery compared with other ischemic stroke subtypes. Also, Nedeltchev et al showed that proximal large vessel occlusion was associated with a more than seven-fold odds of UO [9]. Additionally, Arnold et al have shown that a normal angiogram portends a good prognosis [10]. Cerebral transient ischemic attacks in patients with large vessel occlusion have been found to have a $40 \%$ higher rate of second stroke than those with a normal MRA [11].

This study showed that stroke due to small vessel disease had the best FO. Considering that this stroke is usually small and isolated, it may be true that it has more favorable prognosis for recovery than other stroke subtypes. However, its natu- ral history may not be as benign as commonly presumed. After a 12-year follow-up period, Melkass et al found that the acute index stroke attributable to small vessel disease was associated with poorer long-term survival and higher risk for cardiac death than other stroke subtypes [12]. Additionally, the cumulative effect of its recurrence needs to be considered [13]. The rate of this recurrence has reported variable figures. One study reported a first-year recurrence rate of $2.83 \%$, while another study reported an $83 \%$ rate $[14,15]$. Some studies represent important evidence for a genetic connection and suggest that small vessel disease stroke might result from genetic susceptibility to inflammation-mediated injury in conjunction with atherosclerotic risk factors [16].

In the same direction of my results, Arboix et al found that cardioembolic infarction is also associated with a lower rate of absence of functional limitation at discharge from the hospital, which may be related to its greater size, or higher rate of recurrence [17].

With regard to the cryptogenic stroke, Ntaios et al [18] proved that its cumulative probability of recurrence was similar to cardioembolic strokes, but higher than all the other types of non-cardioembolic stroke, including large artery atherosclerosis $(13 \%)$ and LACs $(13 \%)$. These patients had a favorable functional outcome, defined as MRS $\leq 2(62.5 \%)$, and compared to patients with cardioembolic strokes (32.2\%). Petty et al showed that patients with lacunar infarcts have a better prognosis up to 1 year after onset than those with infarcts due to other stroke etiologies. Compared with other ischemic stroke subtypes, cryptogenic stroke, where no mechanism of stroke is identified, tends to have a better prognosis up to one year following onset [19].

According to the site of the stroke, our study showed that the most UO was in the patients with the TAC $(\mathrm{P}<0.001)$, while the most FO was in patients with lacunar infarction $(\mathrm{P}$ $<0.001)$. The prognosis for stroke recovery may vary by the site of the occluded artery and ischemic brain injury [20]. In agreement with my results, Decarlo et al showed that the

Table 4. Correlation Between the Size of Stroke and its Outcome

\begin{tabular}{|c|c|c|c|c|c|c|}
\hline \multirow{2}{*}{ Lesion size } & \multicolumn{4}{|c|}{ Outcome (N, \%) } & \multirow{2}{*}{ Test } & \multirow{2}{*}{ P value } \\
\hline & Fav & $N=28)$ & & ble $(\mathrm{N}=15)$ & & \\
\hline < 1.5 mm (small) & 18 & 64.2 & 2 & 13.3 & 3.19 & 0.001 \\
\hline $1.5-3 \mathrm{~mm}$ (medium) & 9 & 32.2 & 8 & 53.4 & 1.35 & 0.177 \\
\hline 3 mm (large) & 1 & 3.6 & 5 & 33.3 & 2.86 & 0.007 \\
\hline
\end{tabular}


involvement of total anterior circulation or posterior circulation portends poor prognosis [21]. There is large variation in the results of the prognosis of stroke even in the same anatomical site. Bougusslavsky et al [22] detected a mortality rate of $40 \%$ in cases of POC, whereas Pazdera et al [23] found a mortality rate of $3.6 \%$ at 1 month with encouraging disability status $(28 \%$ with no disability and $51 \%$ with minor disability on MRS), at 1 month post stroke. Strokes in the insular region have been associated with increased mortality, which is often attributed to autonomic dysregulation [24, 25]. Strokes located in the internal capsule demonstrated a worse prognosis for recovery of hand motor function at one year than strokes in the corona radiata or motor cortex after controlling for infarct size [26]. Even the behavior of the stroke may be influenced by the involved artery. Anterior choroidal artery infarctions may be more likely to progress in the first few days after stroke than other subtypes [27, 28]. There are limited and conflicting data regarding border zone infarcts and outcome [29, 30].

The size of acute infarction on neuroimaging studies may be used to estimate stroke outcome [31]. This study confirmed that the larger the size of the ischemic cerebral stroke, the more the UO will be. In agreement with that, Vogt et al [32] and Baird et al [33] found that the initial infarct volume within $72 \mathrm{~h}$ of ischemic stroke onset, as defined by CT or MRI, was an independent predictor of stroke outcome at 90 days, along with age and NIHSS score. In my study, most of the lesions are supratentorial, which may be different from infratentorial ones in which a small infarct can result in severe stroke.

With regard to the clinical severity of ischemic stroke on admission, as estimated by NIHSS, this study proved that the higher the score of NIHSS, the more of the FO. Similar to this result, Coutts et al [34] found that the severity of ischemic stroke on neurologic exam was probably the most important factor affecting short- and long-term outcome. Also, Frankel et al have demonstrated that the NIHSS is a good predictor of stroke outcome [35].

\section{Conclusion}

The outcome of cerebral ischemic stroke may be affected by its subtype. This may help the clinician to tailor better individual plan of management.

\section{References}

1. Lloyd-Jones D, Adams RJ, Brown TM, Carnethon M, Dai S, De Simone G, Ferguson TB, et al. Executive summary: heart disease and stroke statistics - 2010 update: a report from the American Heart Association. Circulation. 2010;121(7):948-954.

2. Amarenco P, Bogousslavsky J, Caplan LR, Donnan GA, Hennerici MG. Classification of stroke subtypes. Cerebrovasc Dis. 2009;27(5):493-501.

3. Goldstein LB, Samsa GP. Reliability of the National Institutes of Health Stroke Scale. Extension to nonneurologists in the context of a clinical trial. Stroke.
1997;28(2):307-310.

4. Toni D, Fiorelli M, De Michele M, Bastianello S, Sacchetti ML, Montinaro E, Zanette EM, et al. Clinical and prognostic correlates of stroke subtype misdiagnosis within 12 hours from onset. Stroke. 1995;26(10):18371840 .

5. Adams HP, Jr., Davis PH, Leira EC, Chang KC, Bendixen $\mathrm{BH}$, Clarke WR, Woolson RF, et al. Baseline NIH Stroke Scale score strongly predicts outcome after stroke: A report of the Trial of Org 10172 in Acute Stroke Treatment (TOAST). Neurology. 1999;53(1):126-131.

6. Banks JL, Marotta CA. Outcomes validity and reliability of the modified Rankin scale: implications for stroke clinical trials: a literature review and synthesis. Stroke. 2007;38(3):1091-1096.

7. Sprigg N, Gray LJ, Bath PM, Lindenstrom E, Boysen G, De Deyn PP, Friis P, et al. Early recovery and functional outcome are related with causal stroke subtype: data from the tinzaparin in acute ischemic stroke trial. J Stroke Cerebrovasc Dis. 2007;16(4):180-184.

8. Lima FO, Furie KL, Silva GS, Lev MH, Camargo EC, Singhal AB, Harris GJ, et al. Prognosis of untreated strokes due to anterior circulation proximal intracranial arterial occlusions detected by use of computed tomography angiography. JAMA Neurol. 2014;71(2):151-157.

9. Nedeltchev K, der Maur TA, Georgiadis D, Arnold M, Caso V, Mattle HP, Schroth G, et al. Ischaemic stroke in young adults: predictors of outcome and recurrence. J Neurol Neurosurg Psychiatry. 2005;76(2):191-195.

10. Arnold M, Nedeltchev K, Brekenfeld C, Fischer U, Remonda L, Schroth G, Mattle H. Outcome of acute stroke patients without visible occlusion on early arteriography. Stroke. 2004;35(5):1135-1138.

11. Coutts SB, Hill MD, Campos CR, Choi YB, Subramaniam S, Kosior JC, Demchuk AM, et al. Recurrent events in transient ischemic attack and minor stroke: what events are happening and to which patients? Stroke. 2008;39(9):2461-2466.

12. Melkas S, Putaala J, Oksala NK, Pohjasvaara T, Oksala A, Kaste M, Karhunen PJ, et al. Small-vessel disease relates to poor poststroke survival in a 12-year follow-up. Neurology. 2011;76(8):734-739.

13. Steinke W, Ley SC. Lacunar stroke is the major cause of progressive motor deficits. Stroke. 2002;33(6):15101516.

14. Sacco RL, Prabhakaran S, Thompson JL, Murphy A, Sciacca RR, Levin B, Mohr JP, et al. Comparison of warfarin versus aspirin for the prevention of recurrent stroke or death: subgroup analyses from the Warfarin-Aspirin Recurrent Stroke Study. Cerebrovasc Dis. 2006;22(1):4-12.

15. Arboix A, Font A, Garro C, Garcia-Eroles L, Comes E, Massons J. Recurrent lacunar infarction following a previous lacunar stroke: a clinical study of 122 patients. J Neurol Neurosurg Psychiatry. 2007;78(12):1392-1394.

16. Revilla M, Obach V, Cervera A, Davalos A, Castillo J, Chamorro A. A -174G/C polymorphism of the interleukin-6 gene in patients with lacunar infarction. Neurosci Lett. 2002;324(1):29-32.

17. Arboix A, Alio J. Cardioembolic stroke: clinical features, 
specific cardiac disorders and prognosis. Curr Cardiol Rev. 2010;6(3):150-161.

18. Ntaios G, Papavasileiou V, Milionis H, Makaritsis K, Vemmou A, Koroboki E, Manios E, et al. Embolic strokes of undetermined source in the athens stroke registry: an outcome analysis. Stroke. 2015;46(8):2087-2093.

19. Petty GW, Brown RD, Jr., Whisnant JP, Sicks JD, O'Fallon WM, Wiebers DO. Ischemic stroke subtypes : a population-based study of functional outcome, survival, and recurrence. Stroke. 2000;31(5):1062-1068.

20. Burke MJ, Vergouwen MD, Fang J, Swartz RH, Kapral MK, Silver FL, Casaubon LK, et al. Short-term outcomes after symptomatic internal carotid artery occlusion. Stroke. 2011;42(9):2419-2424.

21. Di Carlo A, Lamassa M, Baldereschi M, Pracucci G, Consoli D, Wolfe CD, Giroud M, et al. Risk factors and outcome of subtypes of ischemic stroke. Data from a multicenter multinational hospital-based registry. The European Community Stroke Project. J Neurol Sci. 2006;244(1-2):143-150.

22. Bogousslavsky J, Garazi S, Jeanrenaud X, Aebischer N, Van Melle G. Stroke recurrence in patients with patent foramen ovale: the Lausanne Study. Lausanne Stroke with Paradoxal Embolism Study Group. Neurology. 1996;46(5):1301-1305.

23. Pazdera L, Glass TA, Hennessey PM, Chang HM, Wityk RJ, Dewitt L, et al. Outcome at 30 days in the New England medical center posterior circulation registry. Arch Neurol. 2002;59:359-376.

24. Sundar U, Mehetre R. Etiopathogenesis and predictors of in-hospital morbidity and mortality in posterior circulation strokes - a 2 year registry with concordant comparison with anterior circulation strokes. J Assoc Physicians India. 2007;55:846-850.

25. Abboud H, Berroir S, Labreuche J, Orjuela K, Amarenco $\mathrm{P}$, Investigators $\mathrm{G}$. Insular involvement in brain infarction increases risk for cardiac arrhythmia and death. Ann Neurol. 2006;59(4):691-699.

26. Schiemanck SK, Kwakkel G, Post MW, Kappelle LJ, Prevo AJ. Impact of internal capsule lesions on outcome of motor hand function at one year post-stroke. J Rehabil
Med. 2008;40(2):96-101.

27. Ois A, Cuadrado-Godia E, Solano A, Perich-Alsina X, Roquer J. Acute ischemic stroke in anterior choroidal artery territory. J Neurol Sci. 2009;281(1-2):80-84.

28. Derflinger S, Fiebach JB, Bottger S, Haberl RL, Audebert HJ. The progressive course of neurological symptoms in anterior choroidal artery infarcts. Int J Stroke. 2015;10(1):134-137.

29. Joinlambert C, Saliou G, Flamand-Roze C, Masnou P, Sarov M, Souillard R, Saliou-Theaudin M, et al. Cortical border-zone infarcts: clinical features, causes and outcome. J Neurol Neurosurg Psychiatry. 2012;83(8):771775.

30. Bang OY, Lee PH, Heo KG, Joo US, Yoon SR, Kim SY. Specific DWI lesion patterns predict prognosis after acute ischaemic stroke within the MCA territory. J Neurol Neurosurg Psychiatry. 2005;76(9):1222-1228.

31. Schiemanck SK, Kwakkel G, Post MW, Prevo AJ. Predictive value of ischemic lesion volume assessed with magnetic resonance imaging for neurological deficits and functional outcome poststroke: A critical review of the literature. Neurorehabil Neural Repair. 2006;20(4):492502.

32. Vogt G, Laage R, Shuaib A, Schneider A, Collaboration V. Initial lesion volume is an independent predictor of clinical stroke outcome at day 90: an analysis of the Virtual International Stroke Trials Archive (VISTA) database. Stroke. 2012;43(5):1266-1272.

33. Baird AE, Dambrosia J, Janket S, Eichbaum Q, Chaves C, Silver B, Barber PA, et al. A three-item scale for the early prediction of stroke recovery. Lancet. 2001;357(9274):2095-2099.

34. Coutts SB, Hill MD, Simon JE, Sohn CH, Scott JN, Demchuk AM, Group VS. Silent ischemia in minor stroke and TIA patients identified on MR imaging. Neurology. 2005;65(4):513-517.

35. Frankel MR, Morgenstern LB, Kwiatkowski T, Lu M, Tilley BC, Broderick JP, Libman R, et al. Predicting prognosis after stroke: a placebo group analysis from the National Institute of Neurological Disorders and Stroke rt-PA Stroke Trial. Neurology. 2000;55(7):952-959. 